\title{
Anatomical considerations of fascial release in ulnar nerve transposition: a concept revisited
}

\author{
Mark A. Mahan, MD, ${ }^{1}$ Jaime Gasco, MD, ${ }^{2}$ David B. Mokhtee, MD, ${ }^{3}$ and Justin M. Brown, MD $^{4}$ \\ 1Division of Neurological Surgery, Barrow Neurological Institute, St. Joseph's Hospital and Medical Center, Phoenix, Arizona; \\ 2Division of Neurological Surgery, University of Texas Medical Branch, Galveston, Texas; ${ }^{3}$ Tulsa Bone and Joint Associates, \\ Tulsa, Oklahoma; and ${ }^{2}$ Division of Neurosurgery, University of California, San Diego, La Jolla, California
}

\begin{abstract}
OBJECT Surgical transposition of the ulnar nerve to alleviate entrapment may cause otherwise normal structures to become new sources of nerve compression. Recurrent or persistent neuropathy after anterior transposition is commonly attributable to a new distal compression. The authors sought to clarify the anatomical relationship of the ulnar nerve to the common aponeurosis of the humeral head of the flexor carpi ulnaris (FCU) and flexor digitorum superficialis (FDS) muscles following anterior transposition of the nerve.

METHODS The intermuscular septa of the proximal forearm were explored in 26 fresh cadaveric specimens. The fibrous septa and common aponeurotic insertions of the flexor-pronator muscle mass were evaluated in relation to the ulnar nerve, with particular attention to the effect of transposition upon the nerve in this region.
\end{abstract}

RESULTS An intermuscular aponeurosis associated with the FCU and FDS muscles was present in all specimens. Transposition consistently resulted in angulation of the nerve during elbow flexion when this fascial septum was not released. The proximal site at which the nerve began to traverse this fascial structure was found to be an average of 3.9 $\mathrm{cm}(\mathrm{SD} 0.7 \mathrm{~cm})$ from the medial epicondyle.

CONCLUSIONS The common aponeurosis encountered between the FDS and FCU muscles represents a potential site of posttransposition entrapment, which may account for a subset of failed anterior transpositions. Exploration of this region with release of this structure is recommended to provide an unconstrained distal course for a transposed ulnar nerve.

http://thejns.org/doi/abs/10.3171/2014.10.JNS141379

KEY WORDS anatomy; cadaver study; distal compression; reoperation; transposition; ulnar nerve; peripheral nerve

\begin{abstract}
A NTERIOR transposition of the ulnar nerve is a common surgical procedure designed to ameliorate entrapment neuropathy at the elbow. $5,6,14,21,25,31$ Performed for over a century, ${ }^{10}$ the technique of transposition provides direct decompression of the ulnar nerve as well as the elimination of traction during elbow flexion. $5,13,24$ However, anterior transposition may also create new sites of constriction from the fascial structures about the elbow, which act to hold the nerve in its normal anatomical position posterior to the elbow. Proximal to the elbow, these structures include the internal brachial ligament, also known as the "arcade of Struthers," and the medial intermuscular septum. Distal to the elbow, the nerve passes from its retrocondylar location at the elbow into the volar forearm between the humeral and ulnar heads of the flexor carpi ulnaris (FCU) muscle, under a fascial confluence
\end{abstract}

known as the "Osborne band."19 Distal to this structure, the nerve dives below the FCU muscle to enter the fascial sleeve of the flexor digitorum superficialis (FDS) muscle. These fascial layers may constrict the nerve as part of a primary compression neuropathy, ${ }^{4,9,13}$ a problem that may be compounded by anterior transposition if they are not released.

Recently, there have been conflicting reports on the structure of this distal fascial anatomy, as well as on the utilization of similar terms to describe different structures. ${ }^{27}$ Several reports have either indicated an absence of the intermuscular septum between the FDS and the FCU muscles ${ }^{11,15}$ or asserted the presence of new fascial bands, ${ }^{29}$ in contrast to older reports. Furthermore, no study has evaluated the effect of intact fascia after anterior transposition during elbow flexion.

ABBREVIATIONS FCU = flexor carpi ulnaris; FDP = flexor digitorum profundus; FDS = flexor digitorum superficialis . SUBMITTED June 19, 2014. ACCEPTED October 20, 2014.

INCLUDE WHEN CITING Published online April 24, 2015; DOI: 10.3171/2014.10.JNS141379.

DISCLOSURE The authors report no conflict of interest concerning the materials or methods used in this study or the findings specified in this paper. 
To clarify the description of this important anatomical entity, we performed dissections in the fashion of a submuscular transposition ${ }^{22}$ to illustrate these key structures and their relationship to the transposed ulnar nerve in a dynamic model evaluating elbow flexion.

\section{Methods}

The upper extremities of 26 fresh human cadaveric specimens were dissected to investigate the anatomy of the muscular fascia at the level of the flexor-pronator origin. An extended incision was made along the ulnar groove, and the ulnar nerve was unroofed through the retrocondylar retinaculum of the cubital tunnel. The proximal antebrachial fascia overlying the FCU muscle was divided (Fig. 1), but the fascial and aponeurotic components of the humeral head of the FCU and flexor muscle insertions were left intact to investigate their effect on transposition of the ulnar nerve during maximal elbow flexion. The humeral and ulnar heads of the FCU muscle were separated, and the deep fascia of the FCU was divided. The humeral head of the FCU was elevated to identify the thin septum between the FCU and FDS muscles as well as the hiatus within this septum through which the ulnar nerve passes (Fig. 2). The distance from the medial epicondyle to the proximal aspect of this hiatus was measured with the arm in full extension (Fig. 3C).

After assessing the fascial structures at the medial epicondyle, we prepared a bed for the ulnar nerve by opening the antebrachial fascia in Z-plasty fashion, followed by release of the intermuscular septa between the pronator teres muscle, common flexor tendon, and humeral head of the FCU, similar to modifications of the Learmonth submuscular transposition procedure. ${ }^{16,22}$ The nerve was then freed from its bed and transposed into the newly prepared preepicondylar position. The effect of this repositioning upon the nerve was similarly recorded during maximal elbow flexion.

\section{Results}

\section{Superficial Fascia}

All specimens had an intact retrocondylar retinaculum (Fig. 1). There was a discontinuous transition between the antebrachial fascia (of the flexor and pronator muscles) and the retrocondylar retinaculum.

\section{Intermuscular Fascia}

The antebrachial fascia was divided along the long axis of the FCU to expose the muscle fibers. Separation of the humeral and ulnar heads of the FCU demonstrated a deep fascia of the FCU that was of variable thickness between specimens. Proceeding distally, the ulnar nerve was found to pass beneath the deep fascia of the humeral head of the FCU. The ulnar nerve then passed through an aperture in the fascia, separating the FCU from the FDS (Fig. 2). Proximally, the muscle fibers of the FCU insert on this fascia, forming the common aponeurosis of the FCU and FDS. Distally, this fascia serves as the investing fascia of the FDS and flexor digitorum profundus (FDP) muscles. The ulnar nerve was found to pass through this intermus-

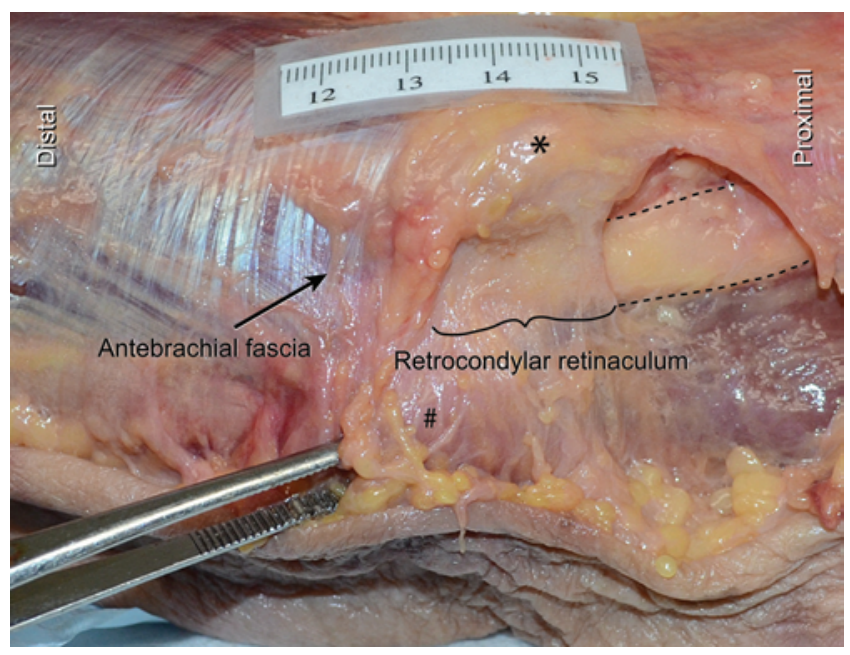

FIG. 1. Identification of the retrocondylar retinaculum, which is distinct from the antebrachial fascia overlying the FCU muscle. Dashed lines indicate the ulnar nerve. ${ }^{*}=$ medial epicondyle; \# = olecranon.

cular septum in all specimens to achieve its normal location in the more distal volar forearm, within the investing fascia of the FDS.

The common aponeurosis was a coalescence of the insertion of the humeral head of the FCU into the investing fascia of the FDS, forming a taut vertical plate between the FCU and FDS. Expressed differently, the intermuscular septum between the humeral head of the FCU and FDS thickens into a fibrous plate, providing the insertion point for both muscles. This was observed as a transition from thin, transparent fascia into a more robust silver and fibrous aponeurosis (Figs. 2 and $3 \mathrm{~A}$ and B).

\section{Effect of the Common Aponeurosis on Transposition}

Transposition of the ulnar nerve into the precondylar position with the common aponeurosis intact resulted in an angulation of the nerve at the site of its passage through this hiatus that was exaggerated during elbow flexion in all specimens (Fig. 4A). The mean distance from the medial epicondyle to the proximal aspect of the hiatus within

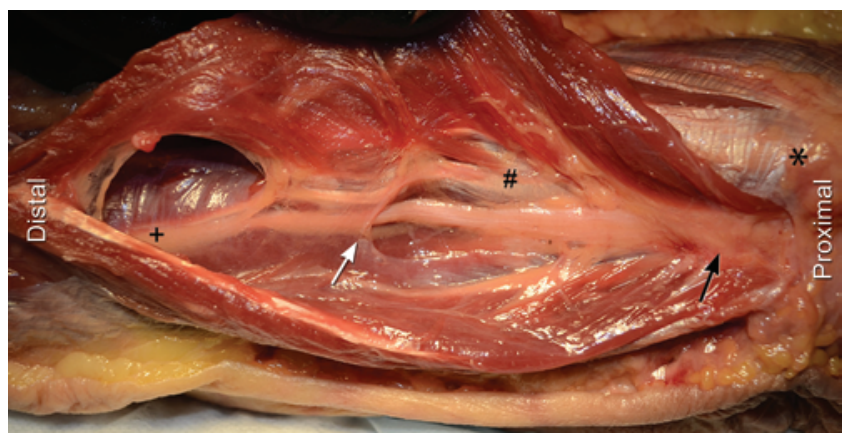

FIG. 2. Passage of the ulnar nerve from the retrocondylar groove into the forearm fascia of the FDS muscle. Black arrow indicates the deep aponeurosis of the FCU; white arrow, the hiatus of the intermuscular septum. ${ }^{*}=$ medial epicondyle; $\#=$ common aponeurosis of the FDS and FCU muscles (note that the intermuscular septum of the FDS and FCU becomes the tendinous common aponeurosis proximally); + = the ulnar nerve deep to the investing fascia of the FDS, located between the FDS and FDP muscles. 

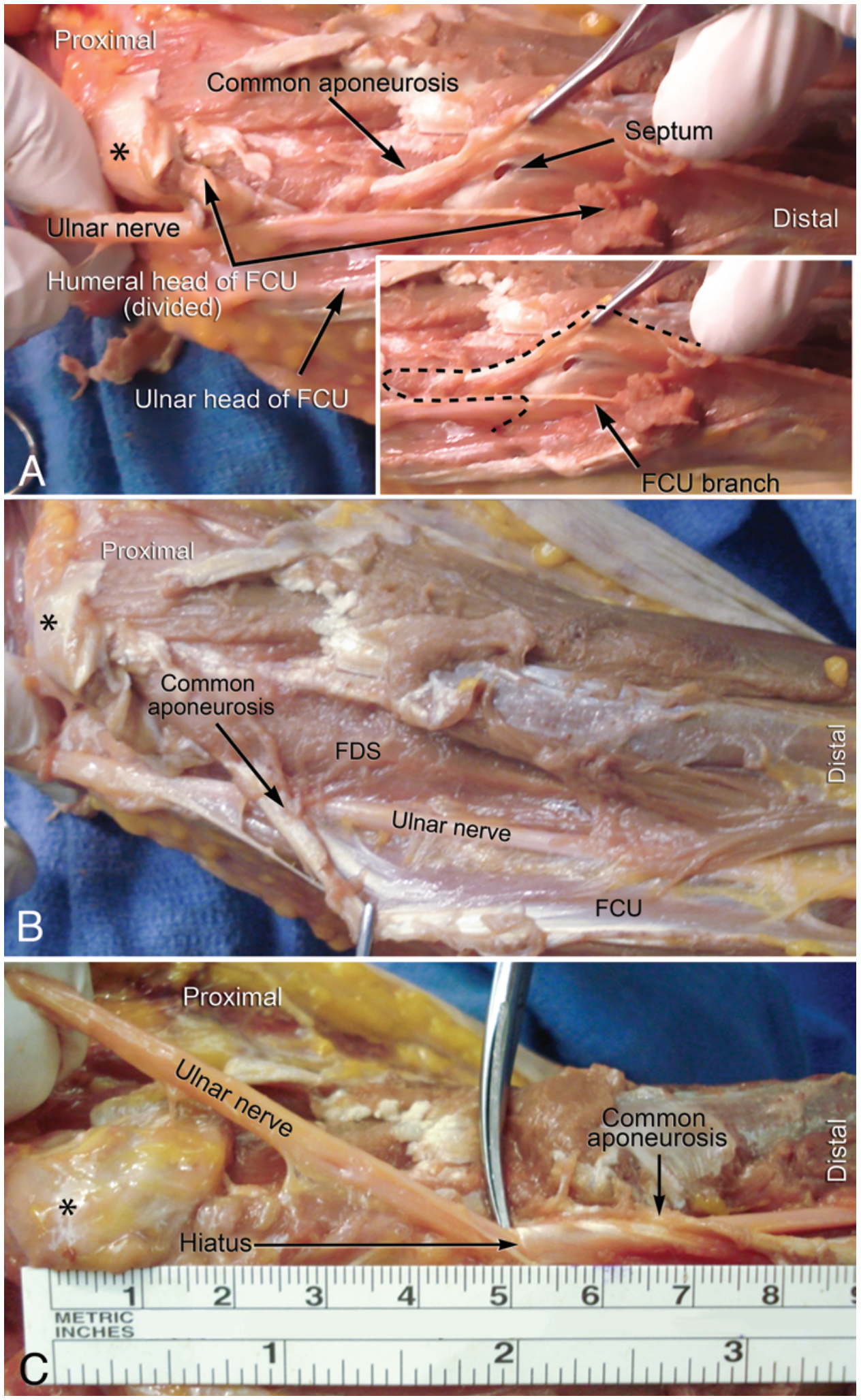

FIG. 3. Identification of the flexor-pronator aponeurosis. A: Ulnar nerve passing underneath the thickest portion of the aponeurosis and penetration through a thin fibrous septum (inset). Dashed line indicates the common aponeurosis. B: Posterior reflection of the aponeurosis demonstrating the separation of the FCU and FDS. C: Anterior mobilization of the ulnar nerve demonstrates tension at the septal hiatus. ${ }^{*}=$ medial epicondyle. 

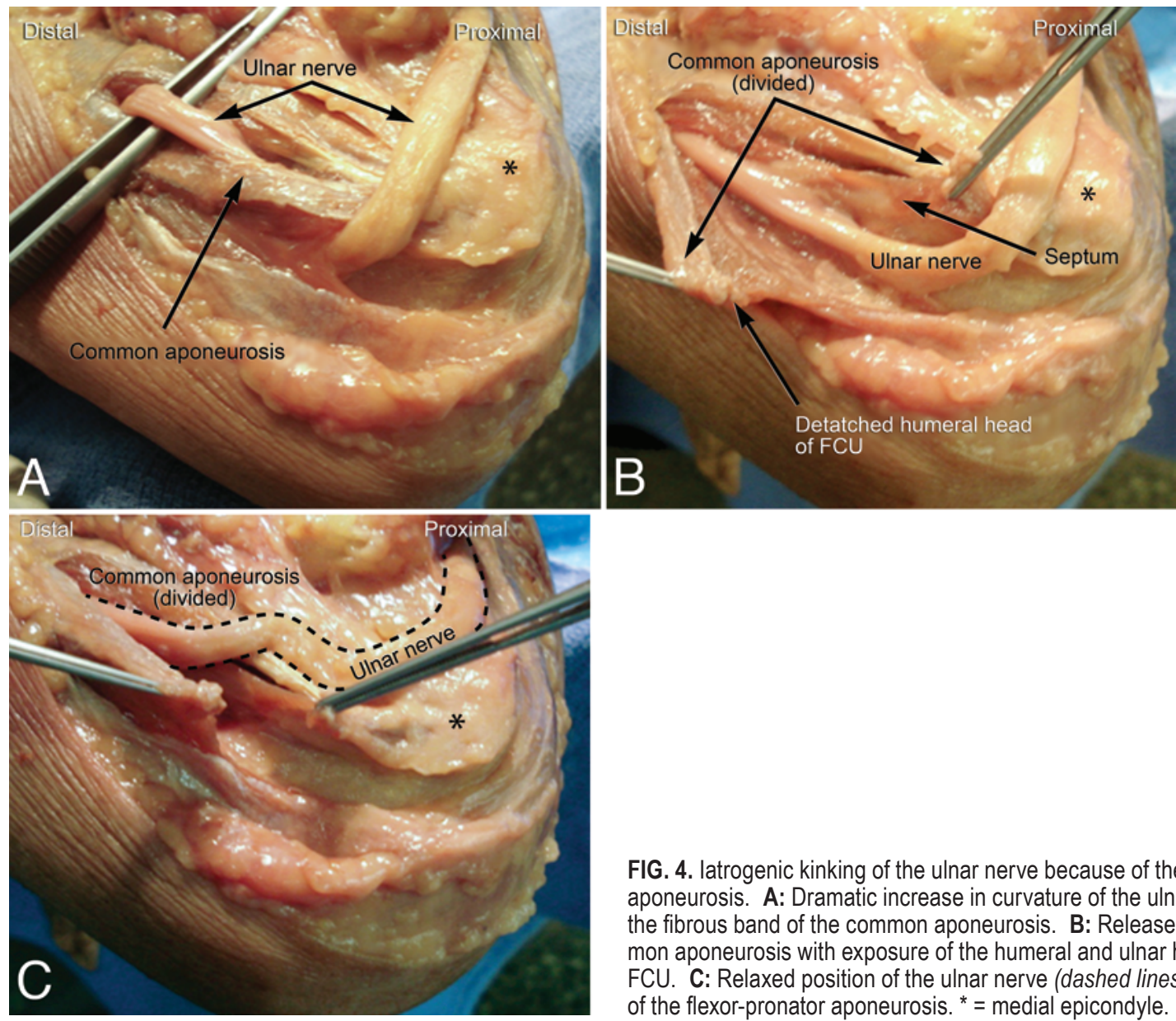

FIG. 4. latrogenic kinking of the ulnar nerve because of the common aponeurosis. A: Dramatic increase in curvature of the ulnar nerve along the fibrous band of the common aponeurosis. B: Release of the common aponeurosis with exposure of the humeral and ulnar heads of the FCU. C: Relaxed position of the ulnar nerve (dashed lines) after division of the flexor-pronator aponeurosis. ${ }^{*}=$ medial epicondyle.

this intermuscular septum (or the site at which this "kinking" occurred) was $3.9 \mathrm{~cm}$ (SD $0.7 \mathrm{~cm}$; Table 1). In right arm specimens, this occurred at a mean distance of $4.0 \mathrm{~cm}$ $(\mathrm{SD} 0.8 \mathrm{~cm})$ and in left arm specimens at $3.9 \mathrm{~cm}(\mathrm{SD} 0.6$ $\mathrm{cm})$ from the medial epicondyle $(\mathrm{p}=0.66$, Mann-Whitney test).

Release of the common aponeurosis of the FCU and FDS relaxed the apparent angulation of the transposed nerve (Fig. 4B and C). Only resection of the common aponeurosis of the FCU and FDS and disinsertion of the humeral origin of the FCU allowed the nerve to travel completely radial to the FCU within the forearm.

\section{Discussion}

Cadaveric dissection confirmed the presence of an intermuscular septum between the FCU and FDS muscles and its associated hiatus through which the ulnar nerve passes. The fascia thickens superficially and proximally to become the common aponeurosis of the FCU and FDS. Left intact, this common aponeurosis resulted in angulation and traction of the ulnar nerve during elbow flexion, which was abrupt in some cases. Iatrogenic angulation at this hiatus may result in a clinical compression syndrome that has been used to explain a subset of suboptimal results following ulnar nerve transposition surgery.,20

TABLE 1. Distance from the center of the medial epicondyle to the deep aponeurosis of the flexor-pronator origin, measured with the elbow in full extension

\begin{tabular}{ccc}
\hline Factor & Left $(\mathrm{cm})$ & Right $(\mathrm{cm})$ \\
\hline Specimen & & \\
\hline 1 & 5.0 & 5.0 \\
\hline 2 & 4.3 & 4.5 \\
\hline 3 & 3.5 & 5.0 \\
\hline 4 & 3.0 & 4.0 \\
\hline 5 & 4.3 & 4.8 \\
\hline 6 & 4.0 & 3.8 \\
\hline 7 & 2.8 & 2.5 \\
\hline 8 & 4.0 & 3.2 \\
\hline 9 & 3.8 & 4.5 \\
\hline 10 & 3.0 & 2.7 \\
\hline 11 & 4.0 & 3.3 \\
\hline 12 & 4.5 & 4.0 \\
\hline Fresh specimen & & \\
\hline 1 & & 4.5 \\
\hline 2 & & 3.5 \\
\hline Mean & 3.9 & 4.0 \\
\hline Standard deviation & 0.6 & 0.8 \\
\hline
\end{tabular}




\section{Prior Anatomical Studies}

Many anatomical studies have investigated the relationship of the ulnar nerve to the flexor-pronator muscles and their associated fascia within the proximal forearm. Despite the scholarly work, inconsistency remains among authors regarding terminology and anatomical relationships. Early studies gave variable names to a common finding; more recent studies revealed inconsistent anatomical relationships, yet were subject to incomplete dissection or incomplete data. No study has examined the dynamic relationship of the forearm fascia and the ulnar nerve during elbow flexion.

Amadio and Beckenbaugh ${ }^{3}$ observed a fascial band common to the FCU and FDS that was a source of compression in 8 patients, which they named the "deep flexorpronator aponeurosis" (the intraoperative photo in Fig. 1 of that publication, depicting a decompression of the distal ulnar nerve in the forearm, demonstrates an entrapment point similar to that in Fig. 3B presented here). The authors also examined 20 cadaveric specimens and found that the nerve pierced through the aponeurosis at the lateral edge of the FCU an average of $5 \mathrm{~cm}$ from the medial epicondyle. Simultaneously, Inserra and Spinner ${ }^{18}$ studied the intermuscular fascial anatomy of the flexor-pronator origin, identifying the common aponeurosis of the FDS and FCU as a source for tethering the ulnar nerve on attempted transposition of the ulnar nerve (Fig. 3 in that publication demonstrates the same finding as in Fig. 3B presented here). Green and Rayan ${ }^{17}$ also confirmed the finding of such a common aponeurosis. They reported findings, similar to our results, indicating that the distal extent of the common flexor aponeurosis averaged $3.7 \mathrm{~cm}$ from the medial epicondyle, although no reference to the degree of elbow flexion was made. Importantly, they found evidence of increased pressures on the ulnar nerve at the site of the common aponeurosis, independent of transposition or proximal decompression. These studies universally found, although the authors described it differently, a fibrous aponeurosis between the FDS and the humeral head of the FCU through which the ulnar nerve traversed, at approximately $4 \mathrm{~cm}$ from the medial epicondyle.

Subsequent anatomical reports failed to arrive at similar conclusions. Gonzalez et al ${ }^{15}$ found a "discrete flexor pronator aponeurosis" in only 17 of $39 \mathrm{arms}$, which formed "an elliptical ... tunnel" $4.2 \mathrm{~cm}$ from the medial epicondyle. They did not relate what was found in the other 22 arms as regards the nerve's passage to the radial side of the FCU. Degeorges and Masquelet ${ }^{11}$ found no aponeurosis between the FCU and the flexor muscles in 54\% of cases; however, no figure in that publication demonstrated dissection of the ulnar nerve up to the medial epicondyle, where the common aponeurosis would have attached. Siemionow and colleagues ${ }^{29}$ split the FCU overlying the ulnar nerve, identifying so-called bands, which they described as analogous to the common aponeurosis of the FCU and FDS. The fascia they depicted is the investing fascia of the FDS, which is why they demonstrated fascia overlying the nerve much further from the medial epicondyle than presented in prior studies. In these later studies, it appears that the anatomy of the intermuscular aponeurosis was not comprehensively explored; the conclusion that the common aponeurosis is either variable or nonexistent is questionable.

\section{Consistent Anatomy of the Fibrous Arcade}

The ulnar nerve passes beneath multiple fascial and muscular structures to enter the volar forearm. After the ulnar nerve exits the retrocondylar groove, it first passes between the humeral and ulnar heads of the FCU underneath a band formed by the fusion of the antebrachial fascia and the deep fascia of the FCU. The ulnar nerve remains under the deep fascia of the FCU until it reaches the radial and deep margin of the muscle. At this point, the ulnar nerve passes through the intermuscular septum between the FCU and FDS (Fig. 5). This septum is thickened proximally, forming the common aponeurosis of the FCU and FDS. The ulnar nerve then continues down the forearm within the enveloping fascia of the FDS, separate from the FCU., 2,18,23,26

The narrow aperture of these structures may participate as a primary cause of cubital tunnel syndrome, as a distinct location from the retrocondylar retinaculum. ${ }^{8,9}$ Similar to the retrocondylar retinaculum, the ulnar nerve is compressed by the fascial structures of the FCU in elbow flexion. ${ }^{4}$ When the ulnar nerve is transposed anteriorly, these anatomical confines become even more pronounced if they are not released. This is because the ulnar nerve must reenter the flexor side of the forearm by passage around the humeral head of the FCU and the common aponeurosis. The common aponeurosis can cause impressive angulation and strangulation of the ulnar nerve in elbow flexion beyond $90^{\circ}$. Furthermore, when a subfascial or submuscular transposition is performed, an intact aponeurosis leaves an exposed fibrous ridge against the nerve, similar to the proximal intermuscular septum between the triceps and brachialis muscles. Remnants of these fibrous septa may irritate the transposed nerve.

\section{Distal Intermuscular Compression as a Source of Recurrent Neuropathy}

The clinical importance of the fascia of the flexorpronator insertion has been echoed through the decades. One of the early descriptions of a submuscular anterior transposition noted the importance of the fibrous bands of the flexor muscles: "The tendons and a few of the musclefibers of the inner head of the flexor carpi ulnaris as well as a few of the tendonous [sic] fibers of the common flexor tendon are divided in order to bury the nerve."1

Sources of recurrent symptoms after surgical decompression are of particular instruction in clinical anatomy. The studies are generally retrospective but serve to highlight the unintended consequences of anatomically incomplete surgery. One of the first retrospective series of reoperations for cubital tunnel syndrome noted frequent compression by "fascial slings" within the FCU.? Gabel and Amadio $^{12}$ found that 20 of 30 patients with recurrent ulnar neuropathy after primary decompression had compression within the flexor-pronator aponeurosis and cubital tunnel. Similarly, when Rogers et al. ${ }^{28}$ reported results of 14 revision surgeries, they placed emphasis on angulation and reactive fibrosis of the ulnar nerve within the FCU. Figures 3 and 5 carefully and clearly depict 

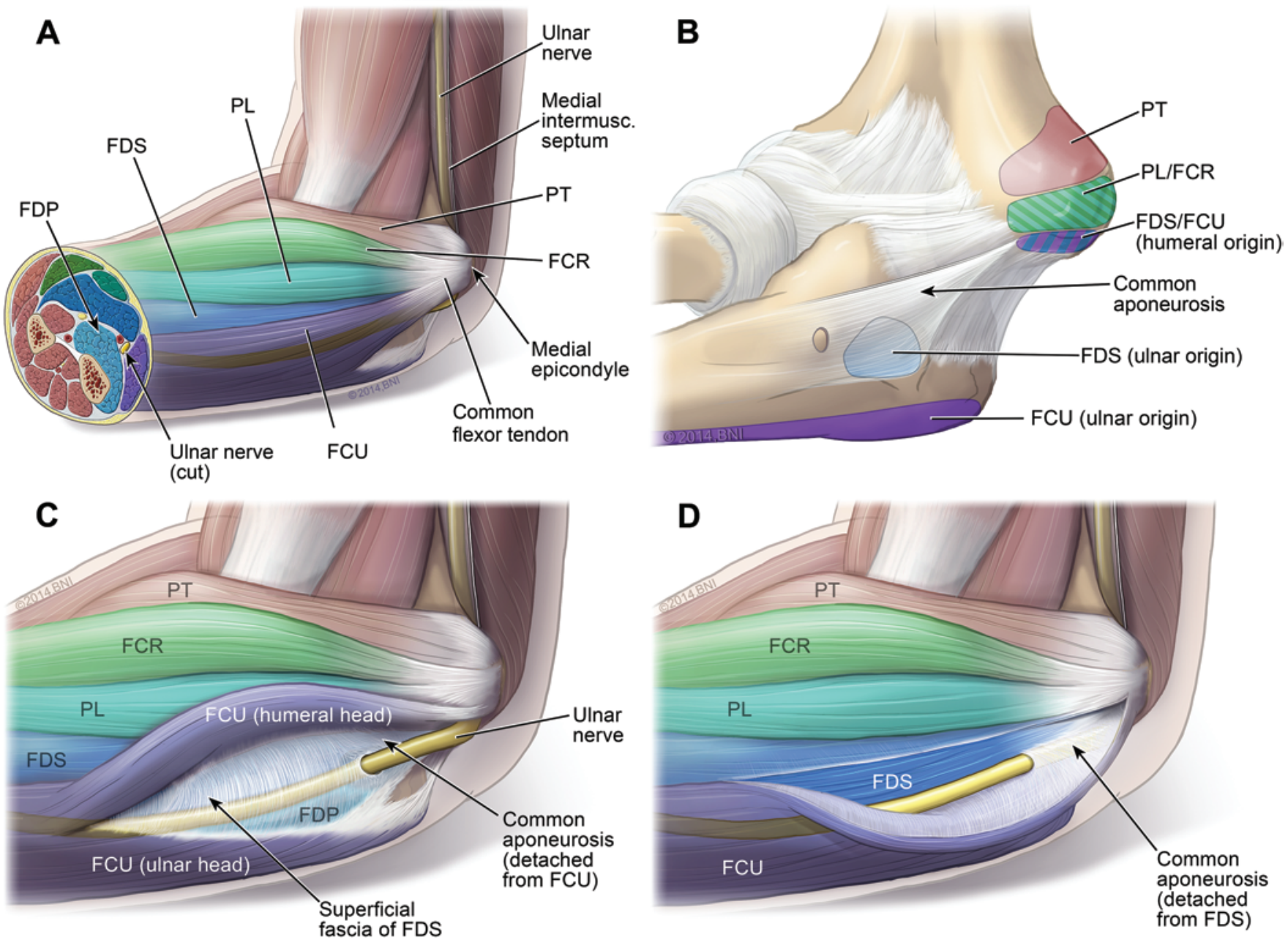

FIG. 5. Artistic representation of the anatomical course of the ulnar nerve in relationship to the musculotendinous structures at the elbow. A: Course of the ulnar nerve from the posterior compartment of the midarm into the flexor compartment of the midforearm. B: Schematic representation of the insertions of the flexor-pronator group and the intermuscular septum and common aponeurosis of the FDS and humeral head of the FCU. C: Elevation of the humeral head of the FCU to expose the course of the ulnar nerve into the investing fascia of the FDS. D: Depression of the humeral head of the FCU to demonstrate the position of the common aponeurosis in restraining anterior translocation of the ulnar nerve. FCR $=$ flexor carpi radialis; intermusc. = intermuscular; PL = palmaris longus; PT = pronator teres. Copyright Barrow Neurological Institute. Published with permission.

angulation and compression at this distal site. Vogel and colleagues $^{30}$ reported on operative findings in 18 patients with failed primary decompression; anterior subcutaneous transpositions were present in 15 . Half of all patients had compression at the common flexor aponeurosis. In a large and recent retrospective review of revision surgeries for failed ulnar nerve decompression, 85 of 100 nerves were compressed and two-thirds of those were compressed distal to the medial epicondyle. ${ }^{23}$

The limited evidence provided in these series suggests that distal revision of the transposed nerve improved ulnar nerve function. In Gabel and Amadio's series, ${ }^{12}$ when the authors addressed the flexor-pronator aponeurosis, all but 1 patient had an outcome that was rated good or excellent. Rogers and colleagues ${ }^{28}$ reported uniformly positive results from revision surgery. Vogel and colleagues ${ }^{30}$ reported a 78\% success rate from revision surgery, but provided insufficient details to allow readers to assess the impact of distal decompression on the results.
Inadequate decompression of the ulnar nerve's fascial transition to the flexor side of the forearm appears to be a major source of surgical failure. Our results confirm that failure to release the intermuscular and, in particular, the thickened common aponeurosis of the FDS and FCU can lead to severe kinking and thus compression of the nerve with anterior transposition.

\section{Conclusions}

As the ulnar nerve transitions from the posterior retrocondylar position into the anterior flexor forearm, it passes beneath the humeral head of the FCU and through an intermuscular septum to continue distally within the fascial compartment of the FDS. This intermuscular septum is thick proximally and superficially, forming the common aponeurosis of the FCU and FDS. If not divided, this taut fascial structure becomes an area of compression and tension after anterior transposition of the ulnar nerve. Com- 
plete release of this structure is essential to complete an anatomically sound anterior transposition of the ulnar nerve.

\section{Acknowledgment}

We appreciate the assistance of Kristen Larson, M.S., C.M.I., for thoughtful and skillful preparation of the anatomical illustrations presented in this manuscript.

\section{References}

1. Adson A: The surgical treatment of progressive ulnar paralysis. Minn Med 1:455-460, 1918

2. Amadio PC: Anatomical basis for a technique of ulnar nerve transposition. Surg Radiol Anat 8:155-161, 1986

3. Amadio PC, Beckenbaugh RD: Entrapment of the ulnar nerve by the deep flexor-pronator aponeurosis. J Hand Surg Am 11:83-87, 1986

4. Apfelberg DB, Larson SJ: Dynamic anatomy of the ulnar nerve at the elbow. Plast Reconstr Surg 51:79-81, 1973

5. Bartels RH, Verhagen WI, van der Wilt GJ, Meulstee J, van Rossum LG, Grotenhuis JA: Prospective randomized controlled study comparing simple decompression versus anterior subcutaneous transposition for idiopathic neuropathy of the ulnar nerve at the elbow: Part 1 . Neurosurgery 56:522-530, 2005

6. Biggs M, Curtis JA: Randomized, prospective study comparing ulnar neurolysis in situ with submuscular transposition. Neurosurgery 58:296-304, 2006

7. Broudy AS, Leffert RD, Smith RJ: Technical problems with ulnar nerve transposition at the elbow: findings and results of reoperation. J Hand Surg Am 3:85-89, 1978

8. Campbell WW, Pridgeon RM, Riaz G, Astruc J, Sahni KS: Variations in anatomy of the ulnar nerve at the cubital tunnel: pitfalls in the diagnosis of ulnar neuropathy at the elbow. Muscle Nerve 14:733-738, 1991

9. Campbell WW, Sahni SK, Pridgeon RM, Riaz G, Leshner RT: Intraoperative electroneurography: management of ulnar neuropathy at the elbow. Muscle Nerve 11:75-81, 1988

10. Curtis BF: Traumatic ulnar neuritis: transplantation of the nerve. J Nerv Ment Dis 25:480-484, 1898

11. Degeorges R, Masquelet AC: The cubital tunnel: anatomical study of its distal part. Surg Radiol Anat 24:169-176, 2002

12. Gabel GT, Amadio PC: Reoperation for failed decompression of the ulnar nerve in the region of the elbow. J Bone Joint Surg Am 72:213-219, 1990

13. Gelberman RH, Yamaguchi K, Hollstien SB, Winn SS, Heidenreich FP Jr, Bindra RR, et al: Changes in interstitial pressure and cross-sectional area of the cubital tunnel and of the ulnar nerve with flexion of the elbow. An experimental study in human cadavera. J Bone Joint Surg Am 80:492501,1998

14. Gervasio O, Gambardella G, Zaccone C, Branca D: Simple decompression versus anterior submuscular transposition of the ulnar nerve in severe cubital tunnel syndrome: a prospective randomized study. Neurosurgery 56:108-117, 2005

15. Gonzalez MH, Lotfi P, Bendre A, Mandelbroyt Y, Lieska N: The ulnar nerve at the elbow and its local branching: an anatomic study. J Hand Surg Br 26:142-144, 2001

16. Green DP: Green's Operative Hand Surgery, ed 5. Philadelphia: Elsevier/Churchill Livingstone, 2005

17. Green JR Jr, Rayan GM: The cubital tunnel: anatomic, histologic, and biomechanical study. J Shoulder Elbow Surg 8:466-470, 1999

18. Inserra S, Spinner M: An anatomic factor significant in transposition of the ulnar nerve. J Hand Surg Am 11:80-82, 1986

19. Kleinman WB: Cubital tunnel syndrome: anterior transposition as a logical approach to complete nerve decompression. J Hand Surg Am 24:886-897, 1999

20. Lowe JB, Mackinnon SE: Failed ulnar nerve decompression, in Midha R, Zager EL (eds): Surgery of Peripheral Nerves: A Case-Based Approach. New York: Thieme, 2008, pp $132-136$

21. Macadam SA, Gandhi R, Bezuhly M, Lefaivre KA: Simple decompression versus anterior subcutaneous and submuscular transposition of the ulnar nerve for cubital tunnel syndrome: a meta-analysis. J Hand Surg Am 33:1314.e1-1314. e12, 2008

22. Mackinnon SE, Novak CB: Compressive neuropathies, in Green DP (ed): Green's Operative Hand Surgery, ed 5. Philadelphia: Elsevier/Churchill Livingstone, 2005, pp 9991046

23. Mackinnon SE, Novak CB: Operative findings in reoperation of patients with cubital tunnel syndrome. Hand (N Y) 2:137-143, 2007

24. Macnicol MF: Extraneural pressures affecting the ulnar nerve at the elbow. Hand 14:5-11, 1982

25. Mowlavi A, Andrews K, Lille S, Verhulst S, Zook EG, Milner S: The management of cubital tunnel syndrome: a metaanalysis of clinical studies. Plast Reconstr Surg 106:327334,2000

26. Nikitins MD, Griffin PA, Ch'ng S, Rice NJ: A dynamic anatomical study of ulnar nerve motion after anterior transposition for cubital tunnel syndrome. Hand Surg 7:177-182, 2002

27. O'Driscoll SW, Horii E, Carmichael SW, Morrey BF: The cubital tunnel and ulnar neuropathy. J Bone Joint Surg Br 73:613-617, 1991

28. Rogers MR, Bergfield TG, Aulicino PL: The failed ulnar nerve transposition. Etiology and treatment. Clin Orthop Relat Res 269:193-200, 1991

29. Siemionow M, Agaoglu G, Hoffmann R: Anatomic characteristics of a fascia and its bands overlying the ulnar nerve in the proximal forearm: a cadaver study. J Hand Surg Eur Vol 32:302-307, 2007

30. Vogel RB, Nossaman BC, Rayan GM: Revision anterior submuscular transposition of the ulnar nerve for failed subcutaneous transposition. Br J Plast Surg 57:311-316, 2004

31. Zlowodzki M, Chan S, Bhandari M, Kalliainen L, Schubert W: Anterior transposition compared with simple decompression for treatment of cubital tunnel syndrome. A meta-analysis of randomized, controlled trials. J Bone Joint Surg Am 89:2591-2598, 2007

\section{Author Contributions}

Conception and design: Mahan, Brown. Acquisition of data: Mahan, Gasco, Mokhtee. Analysis and interpretation of data: Mahan, Brown. Drafting the article: Mahan. Critically revising the article: Mahan. Reviewed submitted version of manuscript: Mahan, Brown. Approved the final version of the manuscript on behalf of all authors: Mahan. Statistical analysis: Mahan, Brown. Administrative/technical/material support: Mahan, Brown. Study supervision: Brown.

\section{Correspondence}

Mark A. Mahan, c/o Neuroscience Publications, Barrow Neurological Institute, St. Joseph's Hospital and Medical Center, 350 W. Thomas Rd., Phoenix, AZ 85013. email: neuropub@dignity health.org. 